\title{
Stable development of the Ukrainian cold logistics market: research by methods of Multidimensional Statistical Analysis
}

\author{
Valerii Matskul ${ }^{1, *}$, Anatoliy Kovalyov ${ }^{1}$, Mariia Saiensus ${ }^{1}$, Diana Okara $^{2}$, and Valentyn \\ Chernyshev $^{1}$ \\ ${ }^{1}$ Odessa National Economic University, 65082 Odessa, Ukraine \\ ${ }^{2}$ Odessa State Academy of Civil Engineering and Architecture, 65029 Odessa, Ukraine
}

\begin{abstract}
The article examines the market of cold logistics in Ukraine (logistics of products, which requires compliance with special temperature conditions). The main problem faced by the authors was the virtual absence of statistical data in this sector of the economy. Therefore, for the study, one of the methods of Multivariate Statistical Analysis was applied, namely, Hierarchical Cluster Analysis. This method made it possible to make a dynamic (for 2017-2020 years) classification of the regions of Ukraine with respect to a latent indicator - the stable development of the cold logistics market. A robust division of 24 regions into three groupsclusters was obtained: "leaders", "middle peasants", "outsiders". The factors-symptoms that had the most significant influence on the formation of a cluster (group of regions) of leaders were determined: the volume of exports and imports, the number of modern multi-temperature logistics warehouse complexes and the income of the population of the region. To assess the environmental impact of the functioning of the cold supply logistics network, an environmental factor was used in the analysis - the volume of $\mathrm{CO}_{2}$ emissions from transport, warehousing, postal and courier activities.
\end{abstract}

\section{Introduction}

In recent years, the global cold logistics market has shown a fairly stable growth. In 2018 , the market volume was about $\$ 160$ billion, and by 2026, experts predict an increase in its volume to $\$ 600$ billion. The leaders in this logistics sector are Asia Pacific and North America. Note that when assessing the level (and directions) of development of world regional markets, experts use the so-called Porter polygon (see, for example, [1]). Cold logistics provides transportation, storage and delivery to the end consumer of products that require special temperature conditions at all elements of the supply chain to extend the storage period and maintain quality. Recently (in connection with the global COVID-19 pandemic), the role of cold logistics in the supply of pharmaceutical products has increased significantly.

\footnotetext{
${ }^{*}$ Corresponding author: valerii.matskul.gmail.com
} 
Against the background of global trends, the Ukrainian cold logistics market does not look very attractive. According to the logistics efficiency index, which is calculated by the World Bank, Ukraine ranks 80th among 160 countries. Therefore, in 2017, the Ministry of Infrastructure, under the auspices of the World Bank Group, developed a draft Strategy for Sustainable Logistics until 2030, which defines the main directions for the development of the logistics market in Ukraine. One of the directions of this Strategy is the expansion of scientific research of the logistics market.

Therefore, the relevance of this work is beyond doubt. It should be noted that the main problem of cold logistics research in Ukraine is the practical lack of reliable specialized operational data in this sector of the economy. In addition, for the delivery of cold products (especially food products) in Ukraine, refrigerators from manufacturers or large retail chains are mainly used.

In contrast to Ukraine, all over the world, large specialized logistics companies are engaged in cold deliveries. In numerous works of foreign authors (see, for example, [2-10]), special attention is paid not only to optimizing the usual transport and operating costs during the operation of cold logistics networks, but also to minimizing the harmful environmental consequences that arise during its operation. Among the recent studies on cold logistics in Ukraine, we note the article of the authors [11], which proposes a solution to optimize the work of a small logistics company (dealing with cold supplies), taking into account the environmental component and the work [12-14], which studies cold logistics as one of the areas of work of a separate large logistics company. In this work, perhaps for the first time, an attempt has been made to comprehensively research the Ukrainian cold logistics market.

\section{Materials and methods}

Various data from the Main Directorates of Statistics of Ukraine and regions (for 20172020 years) were used for the analysis [15]. The preliminary data processing was carried out using MS Excel spreadsheets. During the simulation (modeling and computing), the application package DELL STATISTICA software version 12 was used.

The functioning of any economic entity is characterized by many different indicators. Among these indicators there are clearly measurable ones (for example, production and trade volumes, profit, capital investments, etc.), and there are also hidden ones - latent ones (for example, product quality, competitiveness, efficiency, stable development, etc.). The effect of latent indicators is manifested in clearly measurable signs-symptoms. Multivariate Statistical Analysis (MSA) methods allow to quantify latent features. One of such methods of MSA is the method of Hierarchical Cluster Analysis (HCA).

The essence of this method is that economic objects are considered as points of a multidimensional space of symptoms. Various metrics are chosen as a measure of the proximity of objects. Then the matrix of distances between objects is investigated, their classification (ranking) and clusters (groups) are determined, into which the set of all objects can be divided. The procedure for applying the HCA method should usually consist of 4 stages:

a) first, a hierarchical ranking of objects is carried out, which in some cases makes it possible to determine groups-clusters. Note that for the correct ranking of objects, it is necessary, generally speaking, to add to the studied set two virtual objects: a standard (an object with maximum values of stimulant symptoms) and an anti-standard (an object with minimum values of stimulant symptoms);

b) The K-Means method is then applied to form the clusters. Note that the number of clusters into which the entire set of objects is divided is determined by the researcher; 
c) the next step is to check the robustness of the partition by the methods of Discriminant Analysis (DA). DA allows using linear discriminant functions (which define hyperplanes passing through the centroids of clusters) to check questionable objects for belonging to a particular cluster;

d) In the final step, a two-way combining procedure is applied. Its result is a reordered matrix of feature objects. It shows which signs have had the greatest impact on getting objects into a particular cluster.

\section{Results and discussion}

Regarding the latent feature (latent variable) "stability of cold logistics development", the regions of Ukraine are assessed (the names of regional centers are used for abbreviations): C1 - Vinnytsa, C2 - Volyn, C3 - Dnipropetrovsk, C4 - Donetsk, C5 - Zhytomyr, C6 Zakarpattya, C7 - Zaporizhzhya, C8 - Ivano-Frankivsk, C9 - Kyiv, C10 - Kirovohrd, C11 Luhansk, C12 - Lviv, C13 - Mykolayiv, C14 - Odesa, C15 - Poltava, C16 - Rivne, C17 Sumy, C18 - Ternopyl, C19 - Kharkiv, C20 - Kherson, C21 - Khmelnytskiy, C22 Cherkasy, C23 - Chernivtsi, C24 - Chernihiv.

For each region, the following annual indicators (variables) for 2017-2019 were selected as signs-symptoms (to some extent reflecting the level of development of cold logistics): $x_{i 1}$ - export volume (thousand \$); $x_{i 2}$ - import volume (thousand \$); $x_{i 3}$ - volumes of $\mathrm{CO}_{2}$ emissions from transport, warehousing, postal and courier activities (tons); $x_{i 4}$ is the volume of freight turnover of road transport (thousand tons); $x_{i 5}$ - wholesale turnover (million $\mathrm{UAH}) ; x_{i 6}$ - volume of meat production (thousand tons); $x_{i 7}$ - volume of milk production (thousand tons); $x_{i 8}$ - average monthly total resources of one household (UAH); $x_{i 9}$ - the number of modern multi-temperature logistics complexes (units); $i=\overline{1,24}$. Thus, for each of the years considered, the HCA method is used to study a matrix of objects-variables of dimension $24 \times 9$. Note that all used signs-symptoms (variables) are unidirectional (stimulants, i.e., if greater their value, that better). In addition, an important precondition for conducting MSA is the standardization of variables by replacing:

$$
z_{i j}=\frac{x_{i j}-\overline{x_{j}}}{\sigma_{j}}, j=\overline{1,9},
$$

where are $\overline{x_{j}}$ the mean values, $\sigma_{j}$ are the standard deviations for all objects for the $j$-th variable. This replacement makes the variables dimensionless, their mean values equal to 0 , and their variances equal to 1 . Thus, for any year the matrix $Z_{24 \times 9}=\left(z_{i j}\right) ; i=\overline{1,24} ; j=\overline{1,9}$ will be analyzed. The Euclidean distance $d_{p s}$ between $p$-th and $s$ - th objects was used as a measure of the proximity of objects:

$$
d_{p s}=\sqrt{\sum_{j=1}^{9}\left(z_{p j}-z_{s j}\right)^{2}} .
$$

The results of applying the full ICA procedure for 2017 and 2018 revealed two main features: firstly, the clustering of our set of objects-regions into clusters turned out to be unstable; secondly, the undisputed leader was the $C_{9}$ region - Kyiv, which formed an anomalous cluster (consisting of one object).

Therefore, this region was chosen as a standard-object. Below (see Figures 1, 2) we show one of the results (clustering tree) of the first stage of the HCA method, which demonstrates the identified features. 


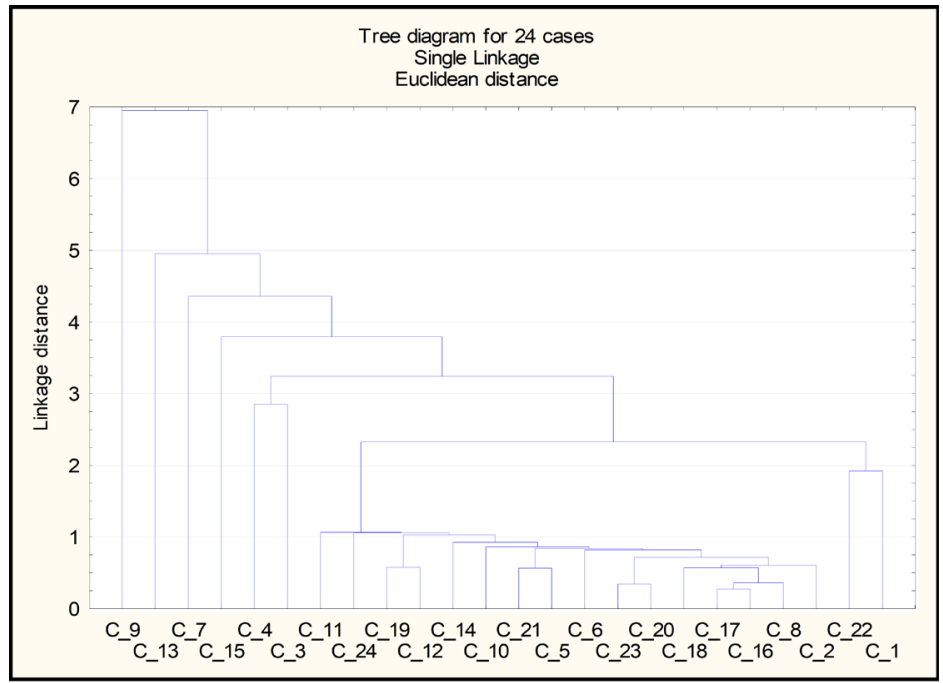

Fig.1. Diagram of distribution the aggregate of objects at the 2017.

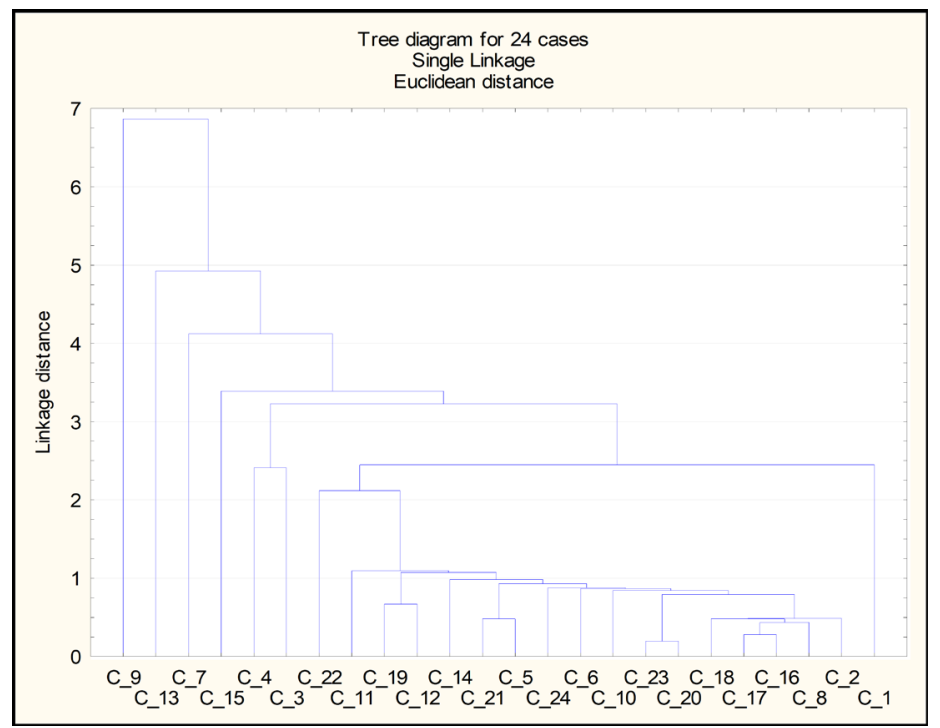

Fig.2. Diagram of distribution the aggregate of objects at the 2018 .

Next, we will show the research results for 2019 obtained using the full HCA procedure. At the first step a), using the "Nearest Neighbor" method and choosing the Euclidean distance $d_{p s}$ between $p$-th and $s$ - th objects:

$$
d_{p s}=\sqrt{\sum_{j=1}^{9}\left(z_{p j}-z_{s j}\right)^{2}}
$$

As a measure of the proximity of objects, we get the too results in the form of a diagrams (see Figures 3, 4). 


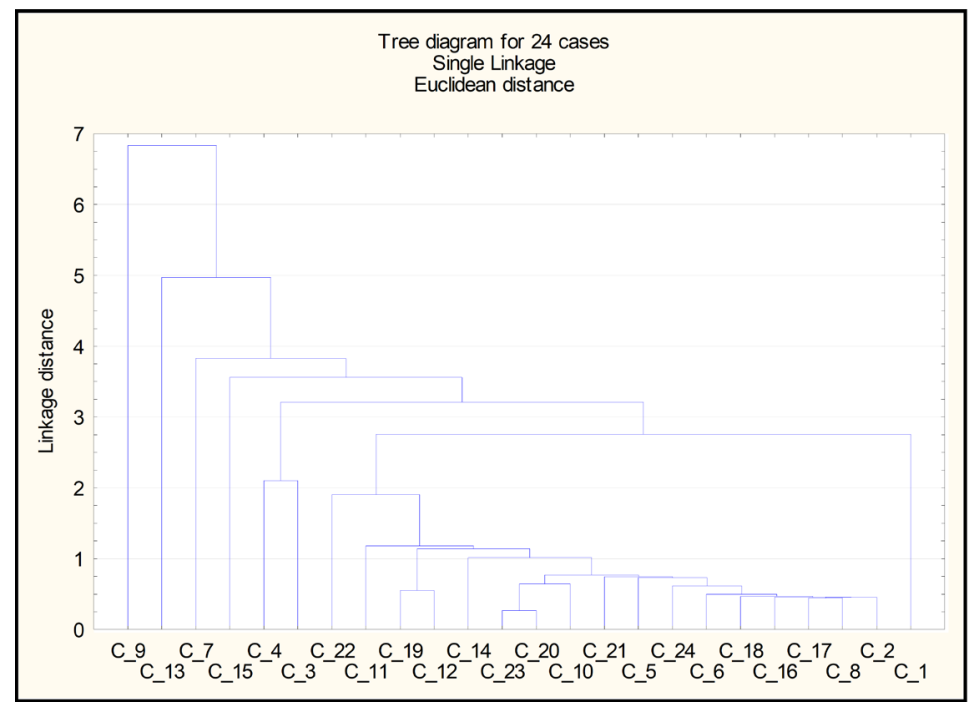

Fig.3. Diagram of distribution the aggregate of objects at the 2019 .

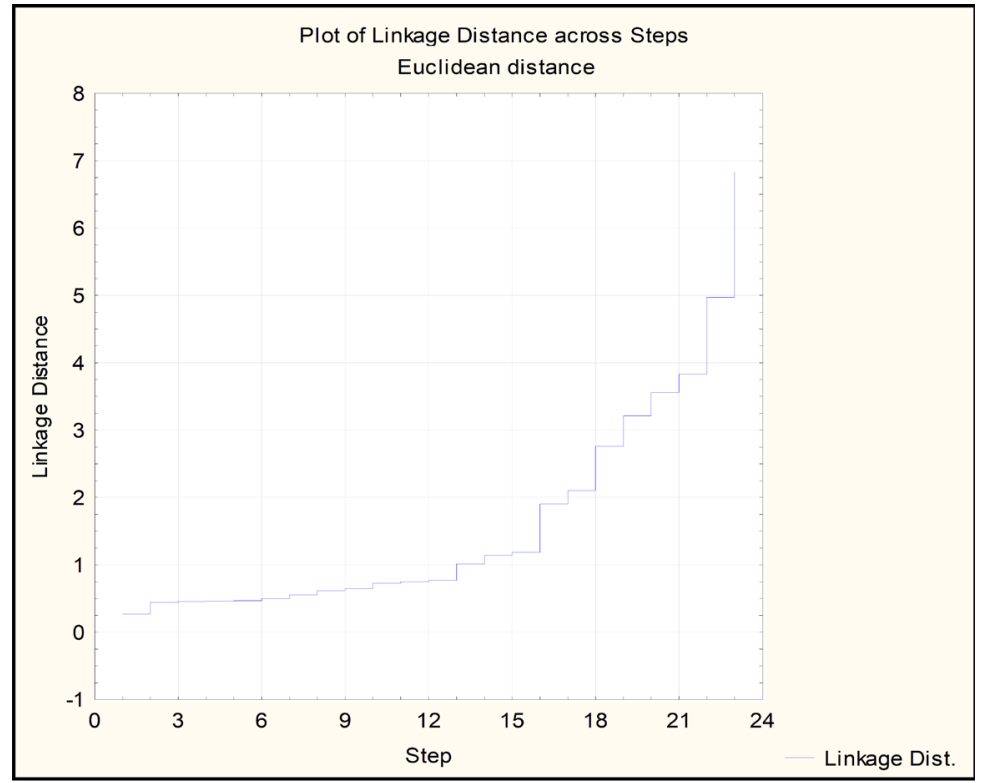

Fig.4. Step-by-step graphics of including the objects into the clusters at the 2019.

At stage b) of the HCA procedure (clustering by the K-means method), we obtain a division of the set of objects (regions of Ukraine) into 3 clusters relative to the latent variable "The level of development of cold logistics". "Leaders": C_3, C_4, C_7, C_9; "Middle peasants": C_2, C_5, C_6, C_8, C_10-C_14, C_16-C_21, C_23, C_24; "Outsiders": C_1, C_15, C_22. For further research, let's add the \{group \} variable to the signs-symptoms (variables) under consideration. The values of the grouping variable \{group are equal to the numbers of the clusters in which the corresponding object fell, and can be found as one of the results of the K-means method - a matrix of distances and distribution of objects by clusters. of some objects to a particular cluster. 
Stage c) of the procedure HCA is used to test the stability of partitioning a set of objects into clusters using Discriminant Analysis methods (in other words, the "separability" of clusters from each other). In our case, there was no need to use discriminant functions to check the belonging The analysis of these results allows us to conclude that it is possible to divide the set of objects into 3 groups-clusters.

Table 1. Classification of objects using posterior probabilities.

\begin{tabular}{|c|c|c|c|c|}
\hline \multirow[b]{2}{*}{ Observations } & \multicolumn{4}{|c|}{$\begin{array}{l}\text { Posterior Probabilities } \\
\text { Incorrect classifications marked with * }\end{array}$} \\
\hline & $\begin{array}{c}\text { Observation } \\
\text { Classification }\end{array}$ & $\begin{array}{l}\text { G_1:1 } \\
\mathrm{p}=, 17\end{array}$ & $\begin{array}{l}\mathrm{G} \_2: 2 \\
\mathrm{p}=, 13\end{array}$ & $\begin{array}{c}\mathrm{G} \_3: 3 \\
\mathrm{p}=, 7\end{array}$ \\
\hline 1 & G_2:2 & 0,00 & 1,00 & 0,00 \\
\hline 2 & G_3:3 & 0,00 & 0,00 & 1,00 \\
\hline 3 & G_1:1 & 1,00 & 0,00 & 0,00 \\
\hline 4 & G_1:1 & 1,00 & 0,00 & 0,00 \\
\hline 5 & G_3:3 & 0,00 & 0,00 & 1,00 \\
\hline 6 & G 3:3 & 0,00 & 0,00 & 1,00 \\
\hline 7 & G_1:1 & 1,00 & 0,00 & 0,00 \\
\hline 8 & G_3:3 & 0,00 & 0,00 & 1,00 \\
\hline 9 & G_1:1 & 1,00 & 0,00 & 0,00 \\
\hline 10 & G_3:3 & 0,00 & 0,00 & 1,00 \\
\hline 11 & G 3:3 & 0,00 & 0,00 & 1,00 \\
\hline 12 & G_3:3 & 0,00 & 0,00 & 1,00 \\
\hline 13 & G_3:3 & 0,00 & 0,00 & 1,00 \\
\hline 14 & G_3:3 & 0,00 & 0,00 & 1,00 \\
\hline 15 & G_2:2 & 0,00 & 1,00 & 0,00 \\
\hline 16 & G 3:3 & 0,00 & 0,00 & 1,00 \\
\hline 17 & G_3:3 & 0,00 & 0,00 & 1,00 \\
\hline 18 & G_3:3 & 0,00 & 0,00 & 1,00 \\
\hline 19 & G_3:3 & 0,00 & 0,00 & 1,00 \\
\hline 20 & G_3:3 & 0,00 & 0,00 & 1,00 \\
\hline 21 & G 3:3 & 0,00 & 0,00 & 1,00 \\
\hline 22 & G_2:2 & 0,00 & 1,00 & 0,00 \\
\hline 23 & G_3:3 & 0,00 & 0,00 & 1,00 \\
\hline 24 & G_3:3 & 0,00 & 0,00 & 1,00 \\
\hline
\end{tabular}

The resulting matrix allows us to assert that the clustering is very robustness. The final step d) HCA is an iterative two-input combining procedure.

It is necessary to construct a sequence of values of the so-called "user threshold" in such a way that it converges to a value that gives a partition of the entire set of objects into the required number of cluster-blocks. Note that in the case of an unstable partition into clusters, this sequence cannot be constructed. The main result of the two-input join procedure is a reordered matrix of objects-variables (Table 2). 
Table 2. Reordered matrix.

\begin{tabular}{|c|c|c|c|c|c|c|c|c|c|}
\hline Regions & \multicolumn{9}{|c|}{ Reordered matrix (Table.sta) } \\
\hline & z1 & z8 & z2 & z9 & z3 & z4 & z6 & z7 & z5 \\
\hline C 1 & $-0,20$ & $-0,02$ & $-0,29$ & $-0,32$ & $-0,27$ & $-0,18$ & 3,82 & 2,16 & $-0,21$ \\
\hline C 22 & $-0,39$ & $-0,39$ & $-0,32$ & $-0,32$ & $-0,43$ & $-0,07$ & 1,74 & 0,41 & $-0,21$ \\
\hline C 15 & 0,01 & 0,43 & $-0,17$ & $-0,32$ & $-0,34$ & 3,14 & $-0,30$ & 2,13 & $-0,21$ \\
\hline C 2 & $-0,44$ & $-0,53$ & $-0,16$ & $-0,32$ & $-0,50$ & $-0,62$ & 0,02 & $-0,16$ & $-0,21$ \\
\hline C 8 & $-0,37$ & $-0,41$ & $-0,26$ & $-0,32$ & $-0,35$ & $-0,59$ & $-0,15$ & 0,19 & $-0,21$ \\
\hline C 17 & $-0,38$ & $-0,60$ & $-0,29$ & $-0,32$ & $-0,48$ & $-0,63$ & $-0,47$ & $-0,01$ & $-0,21$ \\
\hline C 6 & $-0,19$ & $-0,09$ & $-0,15$ & $-0,32$ & $-0,40$ & $-0,70$ & $-0,39$ & $-0,27$ & $-0,21$ \\
\hline C 16 & $-0,52$ & $-0,29$ & $-0,34$ & $-0,32$ & $-0,45$ & $-0,45$ & $-0,41$ & $-0,23$ & $-0,21$ \\
\hline C 5 & $-0,44$ & $-0,64$ & $-0,30$ & $-0,32$ & $-0,42$ & 0,05 & $-0,40$ & 0,71 & $-0,21$ \\
\hline C 21 & $-0,46$ & $-0,53$ & $-0,31$ & $-0,32$ & $-0,41$ & $-0,18$ & $-0,32$ & 1,41 & $-0,21$ \\
\hline C 18 & $-0,53$ & $-0,85$ & $-0,32$ & $-0,32$ & $-0,50$ & $-0,54$ & $-0,39$ & 0,34 & $-0,21$ \\
\hline C 24 & $-0,41$ & $-0,38$ & $-0,33$ & $-0,32$ & $-0,52$ & $-0,63$ & $-0,57$ & 0,67 & $-0,21$ \\
\hline C 12 & 0,04 & $-0,04$ & 0,12 & 0,38 & 0,16 & $-0,33$ & 0,14 & 0,49 & $-0,21$ \\
\hline C 19 & $-0,21$ & $-0,19$ & $-0,11$ & 0,38 & 0,23 & $-0,19$ & $-0,17$ & 0,72 & $-0,21$ \\
\hline C 14 & $-0,22$ & $-0,19$ & $-0,08$ & 0,38 & 0,10 & $-0,22$ & $-0,53$ & $-0,45$ & $-0,20$ \\
\hline C 10 & $-0,44$ & $-0,78$ & $-0,36$ & $-0,32$ & $-0,54$ & 0,03 & $-0,45$ & $-0,57$ & $-0,21$ \\
\hline C 20 & $-0,58$ & $-0,92$ & $-0,33$ & $-0,32$ & $-0,50$ & $-0,57$ & $-0,52$ & $-0,67$ & $-0,21$ \\
\hline C 23 & $-0,60$ & $-1,02$ & $-0,36$ & $-0,32$ & $-0,56$ & $-0,76$ & $-0,52$ & $-0,81$ & $-0,21$ \\
\hline C 11 & $-0,62$ & $-0,48$ & $-0,36$ & $-0,32$ & $-0,01$ & $-0,83$ & $-0,75$ & $-1,67$ & $-0,21$ \\
\hline C 3 & 1,86 & 1,17 & 0,53 & 0,38 & 0,46 & 1,17 & 1,09 & $-1,45$ & $-0,20$ \\
\hline C 4 & 0,81 & 1,96 & $-0,03$ & $-0,32$ & 0,89 & 1,41 & $-0,20$ & $-1,32$ & $-0,21$ \\
\hline C 7 & 0,32 & 0,95 & $-0,14$ & $-0,32$ & 4,17 & $-0,17$ & $-0,48$ & $-1,04$ & $-0,21$ \\
\hline C 9 & 3,95 & 3,32 & 4,60 & 4,53 & 1,13 & 2,28 & 0,77 & $-0,01$ & $-0,10$ \\
\hline C 13 & 0,02 & 0,54 & $-0,23$ & $-0,32$ & $-0,46$ & $-0,42$ & $-0,59$ & $-0,58$ & 4,69 \\
\hline & & & & & & & & & \\
\hline
\end{tabular}

For clarity, we will demonstrate the results of two-input combining in the form of two diagrams (Figures 5, 6).

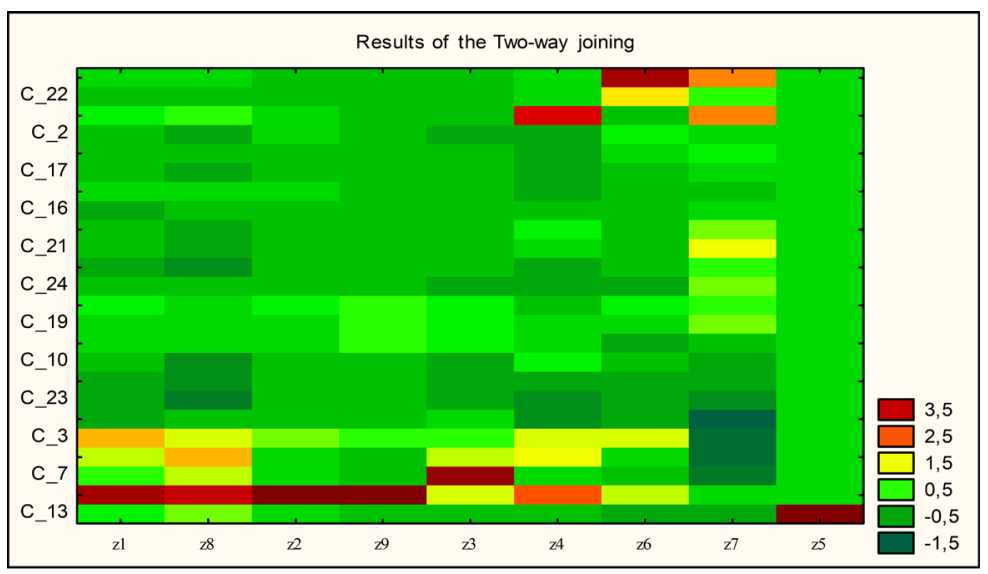

Fig.5. Visualization of the reordered matrix of objects-variables along the level lines (the degree of influence of variables on the formation of clusters). 


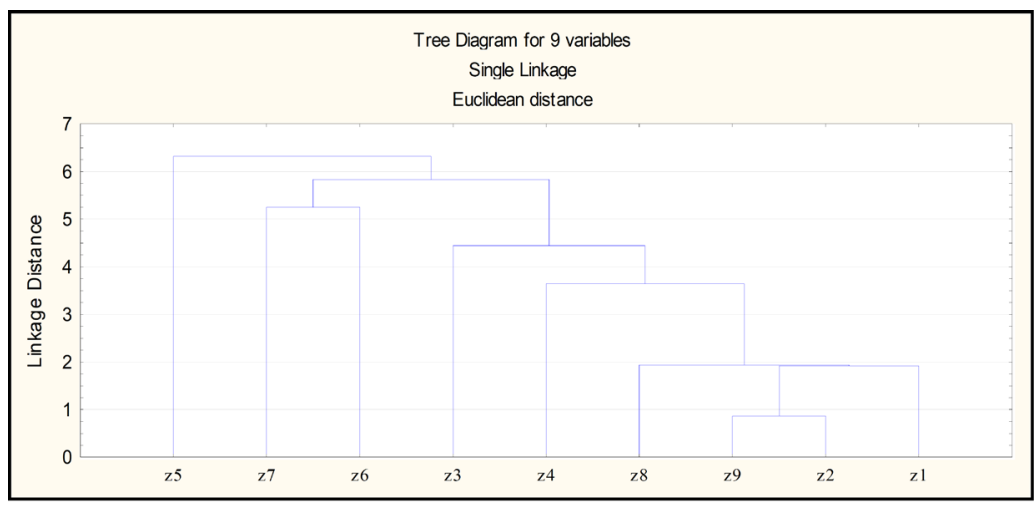

Fig.6. Grouping of signs-symptoms used in the analysis.

Note that a similar procedure of the HCA method was applied to assess the level of stable development of cold logistics in the regions of Ukraine for 2020. In this case, preliminary data from regional statistics for 2020 were used. Similar results were obtained (although the values of some symptom indicators decreased due to the COVID-19 pandemic).

\section{Conclusions}

The study showed that the following factors had the most significant influence on the formation of clusters (especially the group of "leaders") relative to the latent indicator "The level of stable development of cold logistics": the volume of export-import operations (variables x1, x2); income level of the population as the main consumer of cold logistics (variable $\mathrm{x} 8$ ); number of modern multi-temperature warehouse logistics centers (variable x9). In our opinion, for the stable development and realization of the potential of cold logistics in Ukraine, it is necessary: to strengthen multimodality (i.e., the relationship between different modes of transport) when organizing cold supply chains; modernize and expand the transport (refrigerated) and logistics infrastructure, taking into account modern energy-saving and environmental standards; promote trade and specialized logistics companies; improve the qualifications of personnel (in accordance with international standards) providing transport and logistics services; actively implement modern IT in the organization and control of cold supply chains; improve the condition, quality, volumes, efficiency and availability of special logistics data. We especially note that it is necessary at the legislative level to introduce monitoring and restrictions on harmful emissions, which are associated with the operation of refrigerators at all stages of cold supplies.

\section{References}

1. Refrindustry (2019) Global cold chain logistics market 2019-2026, https://refrindustry.com/news/market-research/cold-chain-logistics-market-2019-2026

2. Velázquez Martínez J. C., \& Fransoo J. C. (2017). Sustainable supply chains: a textbook on operations and strategy. New York: Springer.

3. Yan, L., Grifoll, M., \& Zheng, P. (2020). Model and Algorithm of Two-Stage Distribution Location Routing with Hard Time Window for City Cold-Chain Logistics. Applied Sciences, 10(7), 2564. https://doi.org/10.3390/app10072564 
4. Qin, G., Tao, F., \& Li, L. (2019). A Vehicle Routing Optimization Problem for Cold Chain Logistics Considering Customer Satisfaction and Carbon Emissions. International Journal of Environmental Research and Public Health, 16(4), 576. https://doi.org/10.3390/ijerph16040576

5. Qiu, F., Zhang, G., Chen, P.-K., Wang, C., Pan, Y., Sheng, X., \& Kong, D. (2020). A Novel Multi-Objective Model for the Cold Chain Logistics Considering Multiple Effects. Sustainability, 12(19), 8068. https://doi.org/10.3390/su12198068

6. Wang, Z., \& Wen, P. (2020). Optimization of a Low-Carbon Two-Echelon Heterogeneous-Fleet Vehicle Routing for Cold Chain Logistics under Mixed Time Window. Sustainability, 12(5), 1967. https://doi.org/10.3390/su12051967

7. Zhang, L. G., Dong, L., \& Zhou, D. Q. (2013). Dynamic carbon dioxide emissions performance and regional disparity of logistics industry in China-The empirical analysis based on provincial panel data. Systems Engineering, 4, 95-102.

8. Qin G., Tao F., Li L. (2019). A Vehicle Routing Optimization Problem for Cold Chain Logistics Considering Customer Satisfaction and Carbon Emissions. Int. J. Environ. Res. Public Health, (16), 576.

9. Wang X., Li X., Fu D., Vidrih R., Zhang X.. (2020). Ethylene Sensor-Enabled Dynamic Monitoring and Multi-Strategies Control for Quality Management of Fruit Cold Chain Logistics. Sensors, (20), 5830.

10. Zhang, G., Li, G., \& Peng, J. (2020). Risk Assessment and Monitoring of Green Logistics for Fresh Produce Based on a Support Vector Machine. Sustainability, 12(18), 7569. https://doi.org/10.3390/su12187569

11. Matskul V., Kovalyov A., Saiensus M. (2021). Optimization of the cold supply logistics network with an environmental dimension. IOP Conf. Series: Earth and Environmental Science, 628.

12. Hirka O., \& Kolos M. (2020). The logistics solutions is warehouse activity in cold logistics. Economics and business management, (46), 30-35.

13. Yeshchenko, M., Koval, V., \& Tsvirko, O. (2019). Economic policy priorities of the income regulation. Espacios, 40 (38), 11.

14. Dankeieva, O., Solomianiuk, N., Strashynska, L., Fiedotova, N., Soloviova, Y., \& Koval, V. (2021). Application of Cognitive Modelling for Operation Improvement of Retail Chain Management System. TEM Journal, 10(1), 358-367. https://doi.org/10.18421/TEM101-45

15. State Statistics Service of Ukraine (2020). https://www.ukrstat.gov.ua 